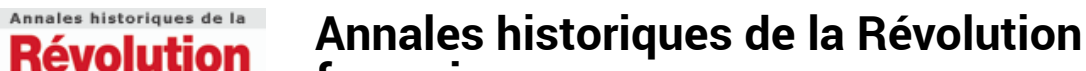

française française

370 | octobre-décembre 2012

Varia

\section{Mary ASHBURN MILLER, A Natural History of Revolution. Violence and Nature in the French Revolutionary \\ Imagination, 1789-1794}

Michel Biard

\section{OpenEdition}

\section{Journals}

Édition électronique

URL : https://journals.openedition.org/ahrf/12558

DOI : $10.4000 /$ ahrf. 12558

ISSN : 1952-403X

Éditeur :

Armand Colin, Société des études robespierristes

Édition imprimée

Date de publication : 1 décembre 2012

Pagination : 260-261

ISBN : 978-2-200-92762-2

ISSN : 0003-4436

Référence électronique

Michel Biard, « Mary ASHBUnn miller, A Natural History of Revolution. Violence and Nature in the French Revolutionary Imagination, 1789-1794 ", Annales historiques de la Révolution française [En ligne], 370 octobre-décembre 2012, mis en ligne le 28 janvier 2013, consulté le 23 avril 2022. URL : http:// journals.openedition.org/ahrf/12558; DOI : https://doi.org/10.4000/ahrf.12558

Ce document a été généré automatiquement le 23 avril 2022.

Tous droits réservés 


\title{
Mary ASHBURN MILLER, A Natural History of Revolution. Violence and Nature in the French Revolutionary Imagination, 1789-1794
}

\author{
Michel Biard
}

\section{RÉFÉRENCE}

Mary ASHBURN MILLER, A Natural History of Revolution. Violence and Nature in the French Revolutionary Imagination, 1789-1794, Ithaca-Londres, Cornell University Press, 2011, 232 p., ISBN : 978-0-801-44942-0, 45 \$.

1 Plus évocateur que le titre, le sous-titre de cet ouvrage indique les pistes que l'auteur se proposait de suivre : repérer les diverses références aux violences de la nature dans l'imaginaire, les écrits et discours des protagonistes de la Révolution française, pour mieux appréhender leur vision des événements en cours. Le choix implique d'emblée que soient écartés d'autres aspects de la nature, pourtant alors eux aussi très présents dans l'imaginaire des hommes du XVIII ${ }^{\mathrm{e}}$ siècle, des scènes champêtres aux paysages réputés "sublimes", du bonheur rousseauiste de la communion avec la nature aux guides qui conduisent les voyageurs sur les chemins, de beautés naturelles en beautés naturelles. Au cœur de l'enquête de Mary Ashburn Miller prennent donc place les tremblements de terre, les volcans, le tonnerre et la foudre, etc. Elle ne manque pas de justifier ce choix, bien entendu, mais celui-ci ne pouvait qu'orienter son travail vers les violences de la Révolution française, soit vers une vision à bien des égards réductrice.

2 L'ouvrage comporte cinq chapitres et leur succession même illustre elle aussi le propos de l'auteur, qui livre là une sorte d'essai et non une recherche qui prétendrait, d'ailleurs en vain, être exhaustive. Le premier chapitre fait presque office d'introduction, en soulignant les antécédents dans la culture du XVIII ${ }^{\mathrm{e}}$ siècle, 
notamment avec le choc du tremblement de terre de Lisbonne en 1755 , ainsi que celui de Sicile et Calabre en 1783. Le deuxième joue de la rhétorique du tremblement de terre avec le séisme politique et social qui ébranle la France en 1789. Le troisième s'intéresse à toutes les métaphores liées à la foudre, le suivant à l'opposition entre la pureté de la Montagne et la corruption du Marais, enfin le cinquième et dernier aux diverses déclinaisons de l'image du volcan. Autant de thèmes qui, on le sait, ont retenu de longue date l'attention des historiens de la Révolution française, comme l'attestent d'ailleurs les références données par l'auteur dans sa bibliographie (où manquent cependant divers travaux, à commencer par ceux de Françoise Brunel sur la Montagne et les montagnards). Autant de thèmes qui donnent donc lieu à un essai composé d'une succession d'études de cas, avec des choix forcément subjectifs. Ainsi, le thème du tremblement de terre s'appuie, d'une part, sur le massacre de la Glacière en Avignon, d'autre part, sur les massacres de septembre 1792 à Paris, là où nombre d'autres exemples auraient pu permettre d'approfondir la démonstration. L'ouvrage relève donc de cette tendance de l'histoire " culturelle » qui entend proposer une réflexion globale tout en prenant appui sur des exemples en nombre volontairement réduit. Dans la même logique, l'auteur a utilisé une douzaine de journaux, des brochures, des discours, etc., là où la presse seule aurait évidemment pu lui offrir un corpus très large, au moins pour les années 1789-1792. Sans doute sommes-nous ici face à un constat qui risque de devenir de plus en plus fréquent, au gré de la mise en ligne de sources numérisées chaque jour plus nombreuses. Fantastique outil de travail, l'Internet modifie en profondeur les activités des chercheurs et désormais une recherche de ce type peut, de fait, être entreprise sans nécessairement passer des semaines entières à la Bibliothèque nationale pour dépouiller des centaines de journaux. Le tout n'a pas à être " jugé », pas davantage qu'il conviendrait de se complaire dans le regret des temps anciens où chacun(e) prenait plaisir à parcourir les originaux dans la grande salle de la rue de Richelieu. En revanche, il convient de ne point être aveugle et de reconnaître les limites inhérentes à ce changement dans nos façons de travailler.

3 Ces réserves étant exposées, le livre de Mary Ashburn Miller permet de retrouver les références employées pour expliquer les événements avec le langage de l'« histoire naturelle ", auxquelles il serait possible d'ailleurs d'ajouter des explications de type religieux, avec notamment le thème du chaos. S'agissant par exemple des massacres de septembre ou de celui de la Glacière, sont mobilisées les "révolutions de la terre ", l'action du «torrent » qui balaie tout sur son passage, celle de la tempête qui " purifie » l'atmosphère, et bien sûr la "justice populaire " aussi imprévisible et impossible à arrêter qu'un tremblement de terre. L'orage, le tonnerre et la foudre offrent tout autant de possibilités, et là l'auteur avait l'embarras du choix tant les sources sont nombreuses. Tel Jupiter, «le» sans-culotte jette ses foudres sur les ennemis de la Révolution (dès lors «foudroyés »), tandis que la «foudre nationale » frappe Lyon qui a osé se rebeller contre la Convention, alors que la campagne pour organiser la récolte du salpêtre suscite là aussi toute une rhétorique spécifique. Je ne m'attarderai pas ici sur le thème de la $\mathrm{M} /$ montagne et $\mathrm{du} \mathrm{M} /$ marais, car ce sont des thèmes en général bien connus des lecteurs français, en revanche force est de regretter l'analyse consacrée par l'auteur à la Fête de l'Être suprême. S'il était bien sûr tout à fait légitime de mentionner le beau livre de Mona Ozouf sur les fêtes révolutionnaires, la lecture des travaux de Michel Vovelle (lui aussi absent de la bibliographie) aurait pu ouvrir d'autres horizons et éviter l'assimilation de cette cérémonie à une "théologie de la Terreur »! Quant aux références au thème du volcan, là aussi hélas la lecture de l'ouvrage n'apporte pas 
grand-chose de neuf, d'autant que l'auteur utilise Le Jugement dernier des rois de Sylvain Maréchal, pièce sur laquelle beaucoup a déjà été écrit.

4 Reste la conclusion du livre qui, se référant aux travaux de Dan Edelstein (The Terror of Natural Right [...], 2009) et à ceux de François Furet, entend démontrer que les Jacobins «de l'an II " fondaient leur politique sur la «loi naturelle» plutôt que sur une Constitution, étaient «obsédés " par la volonté générale qui les mena à la Terreur, usaient d'une rhétorique dans laquelle la violence naturelle permettait de justifier les violences révolutionnaires... et l'auteur de revenir au tremblement de terre de Lisbonne pour affirmer qu'à la fin de 1794 la France "était une nation de Candides », chacun étant désormais prêt «à cultiver son jardin ». Là encore, une vaste bibliographie, tant sur la Terreur que sur la Convention «thermidorienne » et le Directoire, aurait permis de nuancer ces affirmations. En dépit de tout cela, l'ouvrage de Mary Ashburn Miller se lit sans déplaisir et permettra à chacun(e) de découvrir ou redécouvrir une partie de l'imaginaire révolutionnaire. 